\title{
Erratum to: Local and remote tissue injury upon intestinal ischemia and reperfusion depends on the TLR/MyD88 signaling pathway
}

Tatiana Victoni - Fernando Rodrigues Coelho - Alexandre Learth Soares • Andressa de Freitas •

Thomas Secher • Rodrigo Guabiraba - François Erard • Ricardo Martins de Oliveira-Filho • B. Boris Vargaftig • Gregoire Lauvaux • Mamdouh A. Kamal • Bernhard Ryffel • René Moser • Wothan Tavares-de-Lima

Published online: 22 December 2009

(C) Springer-Verlag 2009

Erratum to: Med Microbiol Immunol

DOI 10.1007/s00430-009-0134-5

Same figure were published for part figures of $8 \mathrm{a}$ and $8 \mathrm{~b}$ in the online published article. So author would like to correct the Fig. 8b. See corrected Fig. 8 below.
The online version of the original article can be found under doi:10.1007/s00430-009-0134-5.

T. Victoni - F. R. Coelho - A. L. Soares - R. M. de Oliveira-Filho · B. B. Vargaftig - W. Tavares-de-Lima

Department of Pharmacology, Institute of Biomedical Sciences, University of São Paulo, São Paulo 05508-900, Brazil

\section{A. de Freitas}

Department of Pharmacology,

School of Medicine of Ribeirão Preto,

University of São Paulo, Ribeirão Preto 14049-900, Brazil

T. Secher · R. Guabiraba · F. Erard · M. A. Kamal · B. Ryffel ( () Molecular Immunology and Embryology, University and CNRS, UMR6218, Cedex 2, 45071 Orléans, France

e-mail: bryffel@cnrs-orleans.fr

\section{G. Lauvaux}

CIML-Centre d'Immunologie Marseille-Luminy, Cedex 09, F13288 Marseille, France

\section{R. Moser}

Biomedical Research Foundation,

Lauchefeld 31, 9548 Matzingen, Switzerland

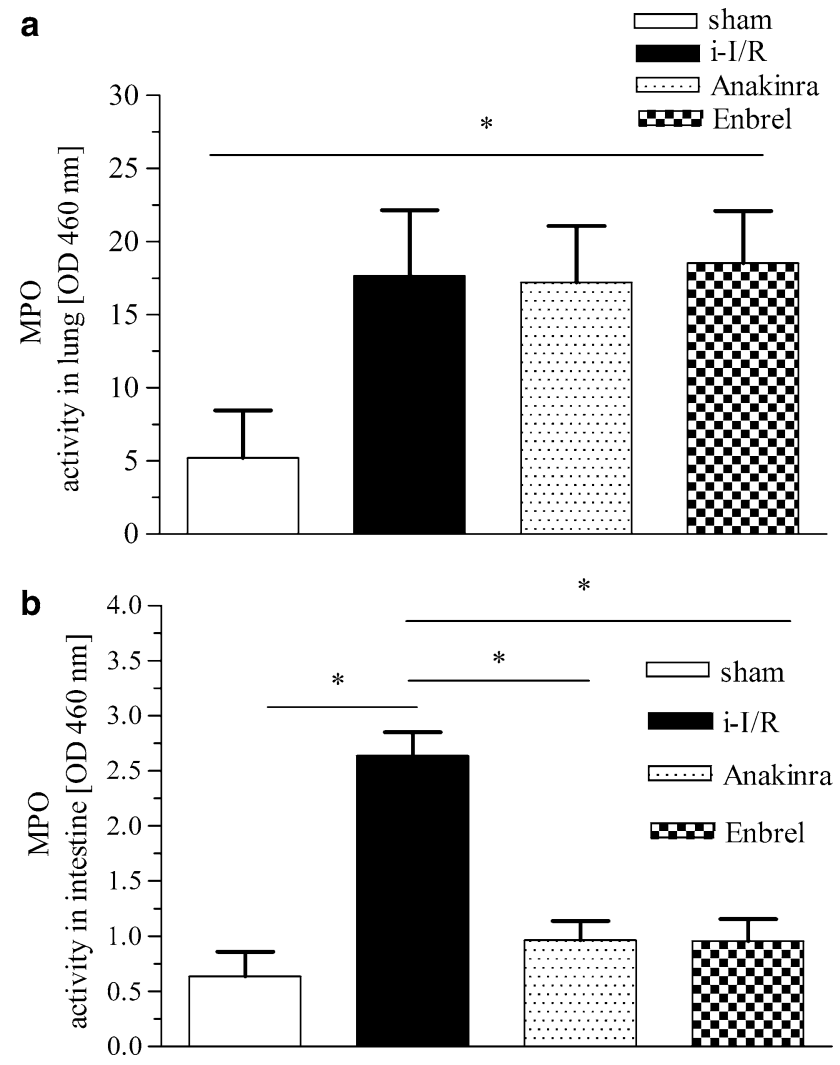

Fig. 8 TNF- $\alpha$ or IL-1 neutralization on ischemia/reperfusion induced neutrophil recruitment in the lung and intestine. Balb/c were treated with saline, or Anakinra or Enbrel, at 5 and $10 \mathrm{mg} / \mathrm{kg}$ twice prior to intestinal ischemia $(45 \mathrm{~min})$ followed by reperfusion $(4 \mathrm{~h})$. MPO activity in the lung (a) and intestine (b) was determined as a measure of neutrophil recruitment. Representative data of two independent studies are given (mean values of 5 mice per group \pm SEM, significant difference $* p<0.05$ ) 